\title{
Acute fibrinous and organizing pneumonia: A case report and literature review
}

\author{
XIAO-YONG XU, FEI CHEN, CHEN CHEN, HUI-MING SUN and BEI-LEI ZHAO \\ Department of Pulmonary and Critical Care Medicine, Nanjing General Hospital of Nanjing Military Command, \\ People's Liberation Army, Nanjing, Jiangsu 210002, P.R. China
}

Received July 8, 2015; Accepted September 1, 2016

DOI: $10.3892 /$ etm.2016.3865

\begin{abstract}
Acute fibrinous and organizing pneumonia (AFOP) is a rare lung disease with distinct histological characteristics that include the diffuse presence of intra-alveolar fibrin, and the absence of eosinophils and hyaline membrane. In the present study, a case of AFOP that was diagnosed by lung biopsy is described. The patient presented with high fever and a cough with expectoration. Computed tomography of the lung showed the presence of bilateral patchy infiltrates, predominantly in the lower lobes. Histopathological examination of lung biopsy from the lower pulmonary lobe confirmed the pathological diagnosis. The patient showed a poor response to treatment with prednisone. Based on a review of literature pertaining to documented AFOP cases, a summary of the clinical features, radiological characteristics, treatment outcomes and prognoses associated with AFOP are presented. The most common pulmonary symptoms included cough, dyspnea and fever. The primary imaging findings in AFOP were consolidation and ground-glass opacity in the bilateral lung.
\end{abstract}

\section{Introduction}

Acute fibrinous and organizing pneumonia (AFOP) is a rare lung disease that was first reported in the year 2002 (1). The distinctive histopathological characteristics of AFOP are intra-alveolar fibrin deposits and associated organizing pneumonia, but without the classical hyaline membrane that is typically associated with diffuse alveolar disease. As only a small number of cases of AFOP have been reported to date, much ambiguity prevails over the clinical features, radiographic characteristics and prognoses of AFOP. In the present

Correspondence to: Dr Bei-Lei Zhao, Department of Pulmonary and Critical Care Medicine, Nanjing General Hospital of Nanjing Military Command, People's Liberation Army, 305 East Zhongshan Road, Nanjing, Jiangsu 210002, P.R. China

E-mail: zhaobeil2002@126.com

Key words: acute fibrinous and organizing pneumonia, review, clinical features study, a patient diagnosed with AFOP, based on histopathological examination of a lung biopsy, is described. Based on a review of literature pertaining to documented AFOP cases, a summary of the clinical features, radiological characteristics, treatment outcomes and prognoses associated with AFOP is presented.

\section{Case report}

A 39-year-old male presented with a 10-day history of high fever and cough with expectoration that was unresponsive to empirical treatment for pulmonary bacterial infection (moxifloxacin $0.4 \mathrm{~g}$ daily for 5 days; Bayer, Leverkusen, Germany) in January 2014 at Nanjing General Hospital of Nanjing Military Command (Nanjing, China). Serial chest computed tomography (CT) scans performed prior to hospitalization revealed enlarging bilateral lung lesions. There was no history of poisoning, exposure to dusty environmental conditions, smoking or alcohol intake. At the time of admission, the patient was looking ill, with slight dyspnea and pyrexia $\left(39.2^{\circ} \mathrm{C}\right)$. Laboratory investigations revealed a white blood cell count of $4.6 \times 10^{9}$ cells $/ 1$ [normal range (NR), $4-10 \times 10^{9}$ cells/1], differential neutrophil count of $68.6 \%$ (NR, 40-70\%) and a C-reactive protein (CRP) level of $39.2 \mathrm{mg} / \mathrm{l}(\mathrm{NR},<10 \mathrm{mg} / \mathrm{l})$ in blood. The clotting parameters were normal. The blood biochemical indices were as follows: Alanine aminotransferase $124 \mathrm{U} / 1$ (NR, <50 U/l), aspartate aminotransferase $124 \mathrm{U} / 1(\mathrm{NR},<50 \mathrm{U} / \mathrm{l})$, gamma-glutamyl transferase $72 \mathrm{U} / 1(\mathrm{NR},<50 \mathrm{U} / 1)$, lactate dehydrogenase $779 \mathrm{U} / 1$ (NR, 90-250 U/l) and creatinine $36 \mu \mathrm{mol} / 1$ (NR, $40-110 \mu \mathrm{mol} / \mathrm{l})$. The patient tested negative for human immunodeficiency virus. Arterial blood gas analysis revealed $\mathrm{PaCO}_{2} 28 \mathrm{mmHg}, \mathrm{PaO}_{2} 59 \mathrm{mmHg}$ and $\mathrm{pH} 7.48\left(\mathrm{FiO}_{2}, 40 \%\right)$. Sputum culture yield was negative. Tests for autoantibody and anti-Epstein-Barr virus, anti-mycoplasma and anti-influenza virus $\mathrm{A}$ antibody were negative. Chest $\mathrm{CT}$ showed bilateral lung consolidation, ground glass opacities and a small quantity of bilateral pleural effusion (Fig. 1). A pulmonary biopsy specimen from the lower lobe confirmed the pathological diagnosis of AFOP (Fig. 2); histopathological examination of lung biopsy specimen with hematoxylin and eosin stain (magnification, x10) showed lymphocytic inflammatory infiltrate and fibroblast proliferation. After diagnosis, $500 \mathrm{mg}$ methylprednisolone (Pfizer, Inc., New York, NY, USA) was 

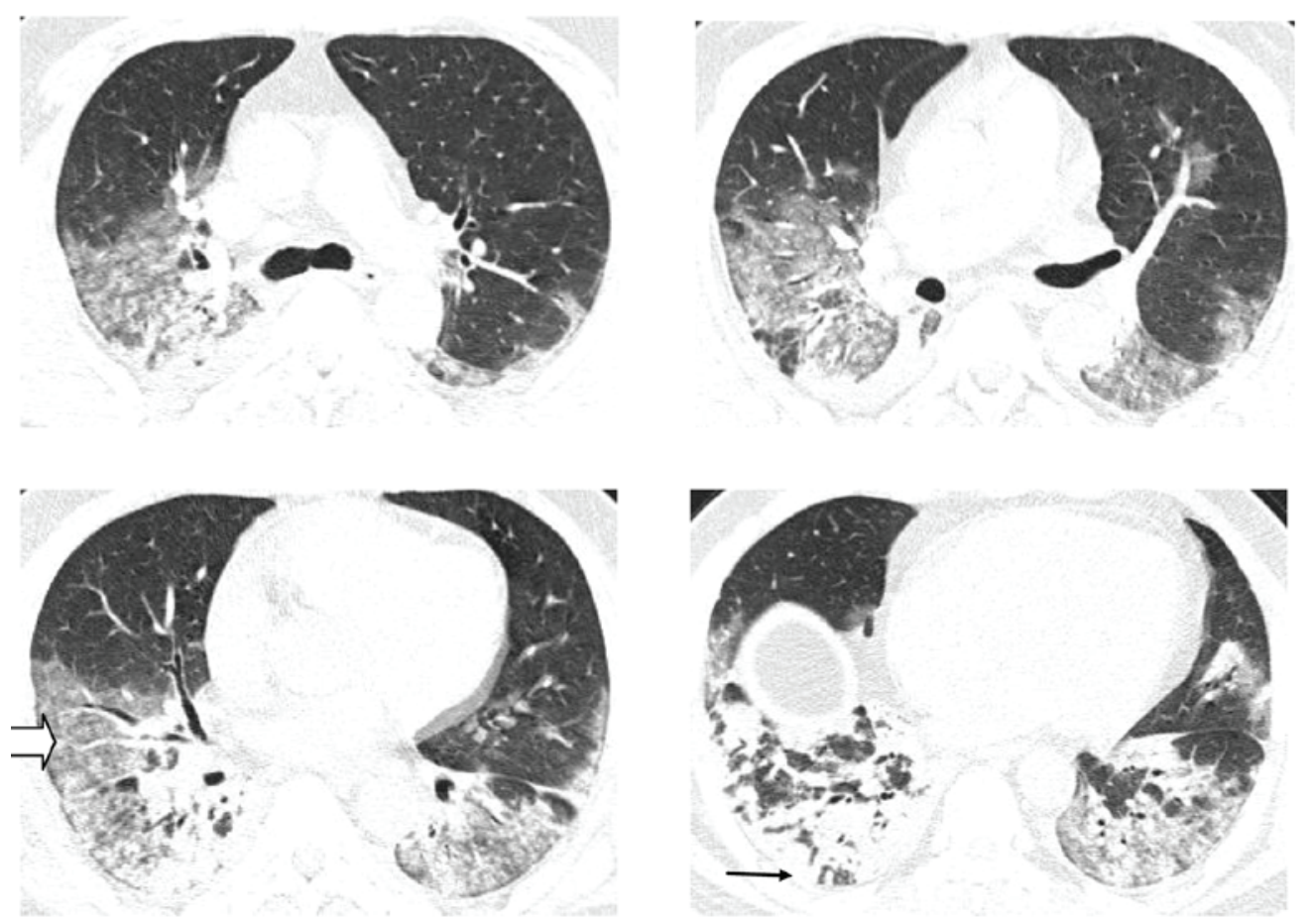

Figure 1. Computed tomography of the chest showing bilateral lung consolidation, ground glass opacities (white arrow) and mild pleural effusion (black arrow).
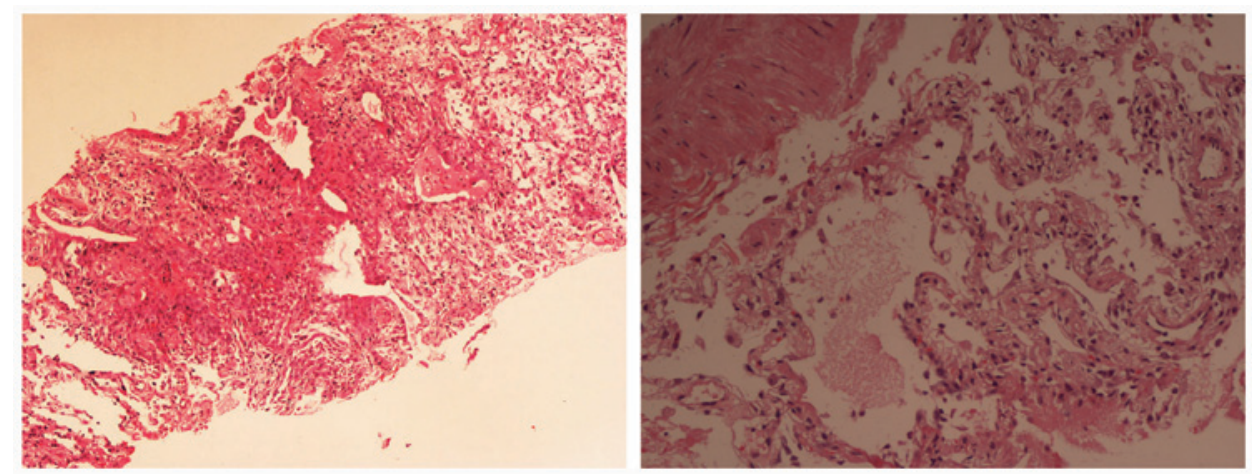

Figure 2. Histopathological examination of lung biopsy specimen with hematoxylin and eosin stain (left panel, magnification, x10; right panel, magnification, $\mathrm{x} 40$ ) showing lymphocytic inflammatory infiltrate and fibroblast proliferation.

administered for 3 days followed by $80 \mathrm{mg}$ for 1 week, but the $\mathrm{SpO}_{2}$ of the patient could not be improved, and he succumbed to mortality 14 days after admission. The patient's wife provided written informed consent.

\section{Literature review}

General literature review. A literature search on PubMed (www.ncbi.nlm.nih.gov/pubmed) and Medline database (www.embase.com) was performed between January 2015 and January 2016 using the key words 'acute fibrinous' and 'organizing pneumonia' or 'AFOP', and yielded a total of 42 articles. English language case reports were included, and manuscripts without adequate details were excluded. Furthermore, relevant Chinese language manuscripts were searched, and duplication was eliminated by combining the reports that happened to refer to the same patient. In addition, reports were removed that lacked data on clinical manifestations, imaging findings, treatment outcomes and prognosis. A total of 24 articles with reference information on 29 patients (including the patient in the present study) qualified for the literature review and served as the study population for the purpose of this analysis (Table I) (2-25). Of 29 patients, 20 were male and 9 were female; the median age was 55 years (range, 10-73 years). There was a considerable variability in the past medical history of AFOP cases and included hypertension, chronic nephrosis, hypothyroidism, diabetes mellitus, hematological disorders (leukemia and myelodysplastic syndrome), pulmonary diseases (cystic fibrosis, asthma and amiodarone-induced interstitial pneumonia), post-lung transplantation for cystic fibrosis, interstitial pneumonia and autoimmune diseases, such as systemic lupus erythematosus (SLE). Smoking appeared not to be a risk factor, since only 5 of the 29 patients had a history of smoking. In addition, 12 patients had no past medical history and were apparently healthy prior to the present illness. 
Table I. Summary of literature reports on acute fibrinous and organizing pneumonia.

\begin{tabular}{lcc}
\hline Author & No. reported patients & Ref. \\
\hline Guimarães et al, 2012 & 1 & 2 \\
Kobayashi et al, 2005 & 1 & 3 \\
Heo et al, 2010 & 1 & 4 \\
Damas et al, 2006 & 1 & 5 \\
Valim et al, 2012 & 1 & 6 \\
Lee et al, 2009 & 1 & 7 \\
Hariri et al, 2010 & 1 & 8 \\
Otto et al, 2013 & 1 & 9 \\
Feng et al, 2014 & 1 & 10 \\
Labarinas et al, 2013 & 1 & 11 \\
Rapaka et al, 2011 & 1 & 12 \\
Bhatti et al, 2009 & 1 & 13 \\
Renaud-Picard et al, 2015 & 1 & 14 \\
Xu et al, 2014 & 1 & 15 \\
Miao et al, 2010 & 1 & 16 \\
Gui et al, 2012 & 2 & 17 \\
Zhang et al, 2010 & 1 & 18 \\
Qiu et al, 2013 & 5 & 19 \\
Garcia et al, 2015 & 1 & 20 \\
Piciucchi et al, 2015 & 1 & 21 \\
Sauter and Butnor, 2014 & 1 & 22 \\
Prahalad et al, 2005 & 1 & 23 \\
Vasu et al, 2009 & 1 & 24 \\
Yokogawa and Alcid, 2007 & 1 & 25 \\
Present case, 2014 & 1 & \\
\hline
\end{tabular}

Table II. Main pulmonary and extrapulmonary symptoms of acute fibrinous and organizing pneumonia (AFOP).

\begin{tabular}{lc}
\hline Symptoms & $\begin{array}{c}\text { No. patients } \\
(\mathrm{n}=29)\end{array}$ \\
\hline Cough & 21 \\
Expectoration & 12 \\
Dyspnea & 15 \\
Hemoptysis & 2 \\
Chest pain & 4 \\
Fever & 16 \\
Fatigue & 1 \\
Anorexia & 2 \\
Loss of weight & 1 \\
Night sweat & 3 \\
\hline
\end{tabular}

Clinical manifestation of AFOP. Clinical manifestation of AFOP appeared to lack specificity with patients presenting with pulmonary and/or extra-pulmonary symptoms. The most common pulmonary symptom was a cough (21/29 patients); 9 patients had a non-productive (dry) cough. Other less common symptoms included progressive dyspnea, cough with expectoration, chest pain and hemoptysis (2/29) (Table II). Vomiting was reported in 3 patients, indicating the probability of bacterial infection.

Fever was the other predominant manifestation, with 16 out of 29 patients having fever as their first symptom at the time of onset. The highest temperature recorded was $39.8^{\circ} \mathrm{C}$, and rarely was it associated with chills and rigors. Most common extra-pulmonary symptoms included fatigue, anorexia, loss of weight and night sweats. However, these symptoms were not common.

The clinical presentation of AFOP in the present study included acute and sub-acute onset. The reported etiology was idiopathic, secondary to pulmonary infection, connective tissue disorders or adverse drug reactions. The onset of illness tended to vary with the etiology with apparently no predictable pattern being discernible. It was typically difficult to ascertain the exact time of onset. The time span from disease onset to initiation of medical treatment ranged between three days and eight months. A number of patients showed signs of infection, such as upper respiratory tract signs and symptoms, along with fever. The most important pulmonary sign was the presence of moist rales in both lower lobes of the lung (14/29 patients), but in 3 patients the abnormal pulmonary signs were confined to a unilateral lobe.

Laboratory tests demonstrated that a small number of patients (4/14) had elevated white blood cells, but the majority of patients (8/11) had elevated CRP. Immunologic tests and anti-neutrophil cytoplasmic antibodies were normal except in one patient with SLE. The various pathological investigations performed included transbronchial lung biopsy (TBLB) in one patient, thoracoscopic lung biopsy in three patients, open-lung biopsy in two patients and pulmonary puncture in 23 patients. All cases were diagnosed as AFOP on the basis of histopathological evidence.

Chest imaging. A number of patients had multiple bilateral lung infiltrative shadows at onset; in these patients, the diagnosis was first suspected on the basis of chest radiography signs. Chest CT was more informative in delineating the pathological chest signs (Table III).

Treatment and prognosis. Hormone therapy was the mainstay of treatment in these patients, with initial dosage varying from prednisone $0.5 \mathrm{mg} / \mathrm{kg} / \mathrm{day}$ to methylprednisolone $240 \mathrm{mg} /$ day. The treatment regimen tended to vary among the patients. Likewise, there was a wide variability in treatment outcomes; ranging between complete resolution and partial resolution, and in case of four patients, deterioration leading to mortality.

\section{Discussion}

AFOP is a rare pathological entity first described by Beasley et al (1). Following this, additional cases of AFOP have been reported. In 2013, the American Thoracic Society/European Respiratory Society statement defined AFOP as a subgroup of idiopathic interstitial lung disease with acute lung injury that is characterized by fibrin deposition in pulmonary alveoli and organization of loose connective tissue (26). The other characteristic feature is the absence 
Table III. Primary imaging findings in acute fibrinous and organizing pneumonia.

$\begin{array}{lc}\text { Imaging findings } & \begin{array}{c}\text { No. patients } \\ (\mathrm{n}=28)^{\mathrm{a}}\end{array}\end{array}$

Ground-glass opacity 13

Consolidation $\quad 24$

Nodular shadows $\quad 8$

Strip/net shadow 5

Interlobular septal thickening $\quad 1$

Unilateral lung 2

Distribution in both lower lobes $\quad 7$

Distribution near the pleura 5

Distribution in bronchial vascular bundles $\quad 7$

Low density shadow 0

Halo sign 3

Reserved halo sign $\quad 1$

Hydrothorax 6

Pneumothorax 0

a Computed tomography findings were not documented in one patient; 28 patients were enrolled.

Table IV. Analysis of patients with poor prognosis.

\begin{tabular}{lcc}
\hline Grouping & $\begin{array}{c}\text { Mortality at post- } \\
\text { treatment visit }\end{array}$ & $\begin{array}{c}\text { Survival at post- } \\
\text { treatment visit }\end{array}$ \\
\hline Age $( \pm$ SD) & $39.3 \pm 19.0$ & $54.5 \pm 16.5$ \\
Gender (male:female) & $3: 1$ & $17: 8$ \\
Symptoms (n=29), n & & \\
Dyspnea & $3 / 4$ & $12 / 25$ \\
Fever & $2 / 4$ & $14 / 25$ \\
Computed tomography & & \\
(n=28), n & & \\
Ground-glass opacity & $2 / 4$ & $11 / 24$ \\
Consolidation & $4 / 4$ & $20 / 24$ \\
Nodular shadows & $1 / 4$ & $7 / 24$ \\
Hydrothorax & $3 / 4$ & $3 / 24$ \\
\hline
\end{tabular}

$\mathrm{SD}$, standard deviation.

of diffuse pulmonary alveolar injury, hyaline membrane formation and no eosinophil infiltration or granuloma formation (26). Although all cases were diagnosed on the basis of histopathological evidence, there were marked differences in clinical manifestations, treatment and prognosis.

AFOP is a group of illnesses marked by a considerable heterogeneity with respect to clinical and pathological changes. The disease etiology is idiopathic or secondary to other diseases, such as viral infection, connective tissue disorders and adverse drug reactions. Furthermore, owing to the heterogenous clinical presentation, the cause of AFOP is typically ambiguous.
The most common symptoms of AFOP identified in previous literature were cough, fever and dyspnea, while chest pain and hemoptysis were relatively less frequent. The clinical picture appears to be similar to that in other forms of idiopathic interstitial pneumonia; however, fever that is more common in AFOP as compared with other forms of interstitial pneumonia.

Radiographic chest findings included consolidation and bilateral ground-glass shadows with no low-density shadows. The clinical manifestations of AFOP have been summarized in a number of reports $(8,10,15,17)$. As per these reports, the majority of patients had presented with organizing pneumonia along with multiple plaques, and diffuse increase in dense shadows in pulmonary alveoli distributed in outer zone and bilateral boundaries (15). However, a small number of the patients presented with randomly distributed nodular shadows. The etiology as well as the pathological basis of AFOP requires further research in order to facilitate its distinction from tuberculosis and tumors.

Out of the four mortalities on record among the study population in the current report, there were 3 males and 1 female. The key distinguishing factors in this study was a higher proportion of cases with dyspnea and lack of nodular shadows on chest radiographs, while there was no significant difference in the proportion of patients manifesting fever. In addition, it was identified that the development of hydrothorax in AFOP was a poor prognostic indicator (Table IV). However, findings from the present study require further evaluation and validation in larger series.

In conclusion, the current report presents a case of AFOP that has a rapid onset and progress, is not secondary to other diseases, shows no improvement in response to glucocorticoid hormone treatment and has a poor prognosis, and summarizes the key aspects of this rare disease based on a review of available published literature. Given the ambiguous etiology and heterogenous clinical presentation, there is likely to be a significant under-reporting of AFOP. In other words, the incidence rate of AFOP could be much higher than what has so far been reported in the literature. Therefore, the key clinical aspects underlined in this report should pave the way for further research on AFOP.

\section{References}

1. Beasley MB, Franks TJ, Galvin JR, Gochuico B and Travis WD: Acute fibrinous and organizing pneumonia: A histological pattern of lung injury and possible variant of diffuse alveolar damage. Arch Pathol Lab Med 126: 1064-1070, 2002.

2. Guimarães C, Sanches I and Ferreira C: Acute fibrinous and organising pneumonia. BMJ Case Rep 2012: bcr0120113689, 2012.

3. Kobayashi H, Sugimoto C, Kanoh S, Motoyoshi K and Aida S: Acute fibrinous and organizing pneumonia: Initial presentation as a solitary nodule. J Thorac Imaging 20: 291-293, 2005.

4. Heo JY, Song JY, Noh JY, Yong HS, Cheong HJ and Kim WJ: Acute fibrinous and organizing pneumonia in a patient with HIV infection and Pneumocystis jiroveci pneumonia. Respirology 15: 1259-1261, 2010.

5. Damas C, Morais A, Moura CS and Marques A: Acute fibrinous and organizing pneumonia. Rev Port Pneumol 12: 615-620, 2006.

6. Valim V, Rocha RH, Couto RB, Paixão TS and Serrano EV: Acute fibrinous and organizing pneumonia and undifferentiated connective tissue disease: A case report. Case Rep Rheumatol 2012: 549298, 2012. 
7. Lee SM, Park JJ, Sung SH, Kim Y, Lee KE, Mun YC, Lee SN and Seong CM: Acute fibrinous and organizing pneumonia following hematopoietic stem cell transplantation. Korean J Intern Med 24: $156-159,2009$.

8. Hariri LP, Unizony S, Stone J, Mino-Kenudson M, Sharma A, Matsubara $\mathrm{O}$ and Mark EJ: Acute fibrinous and organizing pneumonia in systemic lupus erythematosus: A case report and review of the literature. Pathol Int 60: 755-759, 2010.

9. Otto C, Huzly D, Kemna L, Hüttel A, Benk C, Rieg S, Ploenes T, Werner $M$ and Kayser G: Acute fibrinous and organizing pneumonia associated with influenza $\mathrm{A} / \mathrm{H} 1 \mathrm{~N} 1$ pneumonia after lung transplantation. BMC Pulm Med 13: 30, 2013.

10. Feng AN, Cai HR, Zhou Q, Zhang YF and Meng FQ: Diagnostic problems related to acute fibrinous and organizing pneumonia: Misdiagnosis in 2 cases of lung consolidation and occupying lesions. Int J Clin Exp Pathol 7: 4493-4497, 2014

11. Labarinas S, Gumy-Pause F, Rougemont AL, Baerlocher G, Leibundgut EO, Porret N, Schäppi MG, Barazzone-Argiroffo C, Passweg J, Merlini L, et al: Is acute fibrinous and organizing pneumonia the expression of immune dysregulation? J Pediatr Hematol Oncol 35: 139-143, 2013.

12. Rapaka V,Hussain MA, Niazi M and Diaz-Fuentes G: Severe acute fibrinous and organizing pneumonia causing acute respiratory distress syndrome and shock. J Bronchology Interv Pulmonol 18 269-273, 2011.

13. Bhatti S, Hakeem A, Torrealba J, McMahon JP and Meyer KC: Severe acute fibrinous and organizing pneumonia (AFOP) causing ventilatory failure: Successful treatment with mycophenolate mofetil and corticosteroids. Respir Med 103: 1764-1767, 2009

14. Renaud-Picard B, Dégot T, Biondini D, Weingertner N, Reeb J, Chenard MP and Kessler R: Successful lung retransplantation in a patient with acute fibrinous and organizing pneumonia: A case report. Transplant Proc 47: 182-185, 2015.

15. Xu Y, Ding Hz, Hu T and Qh W: Acute fibrinous and organizing pneumonia: A case report and review of the literature. Lin Chuang Fei Ke Za Zhi 1: 186-189, 2014 (in Chinese).

16. Miao LY, Dai JH, Gui XH, Zhang DP and FQ M: The clinical pathological features of acute fibrinous and organizing pneumonia. Lin Chuang Fei Ke Za Zhi 9: 1260-1262, 2010 (in Chinese).
17. Gui XH, Zhang YW, Dai JH, Cai HR, Xiao YL, Meng FQ and Chen B: Acute Fibrinous and Organizing Pneumonia: Two case reports and literature review. Chinese Journal of Respiratory and Critical Care Medicine 6: 558-561, 2012.

18. Zhang J, Fang QH, Feng RE, Ma YM, Cao Y and Wang RG Acute fibrinous and organizing pneumonia: A case report and review of the literature. Zhonghua Jie $\mathrm{He} \mathrm{He} \mathrm{Hu} \mathrm{Xi} Z \mathrm{Za}$ Zhi 33: 892-895, 2010 (In Chinese).

19. Qiu YY, Miao LY, Cai HR, Xiao YL, Ye Q, Meng FQ and Feng AN: The clinicopathological features of acute fibrinous and organizing pneumonia. Zhonghua Jie $\mathrm{He} \mathrm{He} \mathrm{Hu}$ Xi Za Zhi 36: 425-430, 2013 (In Chinese).

20. Garcia BA, Goede T and Mohammed TL: Acute fibrinous organizing pneumonia: A case report and literature review. Curr Probl Diagn Radiol 44: 469-471, 2015.

21. Piciucchi S, Dubini A, Tomassetti S, Casoni G, Ravaglia C and Poletti V: A case of amiodarone-induced acute fibrinous and organizing pneumonia mimicking mesothelioma. Am J Respir Crit Care Med 191: 104-106, 2015.

22. Sauter JL and Butnor KJ: Expanding the spectrum of pulmonary histopathological manifestations of anti-synthetase syndrome: Anti-EJ-associated acute fibrinous and organizing pneumonia. Histopathology 65: 581-582, 2014.

23. Prahalad S, Bohnsack JF, Maloney CG and Leslie KO: Fatal acute fibrinous and organizing pneumonia in a child with juvenile dermatomyositis. J Pediatr 146: 289-292, 2005.

24. Vasu TS, Cavallazzi R, Hirani A and Marik PE: A 64-year-old male with fever and persistent lung infiltrate. Respir Care 54: 1263-1265, 2009

25. Yokogawa N and Alcid DV: Acute fibrinous and organizing pneumonia as a rare presentation of abacavir hypersensitivity reaction. AIDS 21: 2116-2117, 2007.

26. Travis WD, Costabel U, Hansell DM, King TE Jr, Lynch DA, Nicholson AG, Ryerson CJ, Ryu JH, Selman M, Wells AU, et al; ATS/ERS Committee on Idiopathic Interstitial Pneumonias: An official American thoracic society/European respiratory society statement: Update of the international multidisciplinary classification of the idiopathic interstitial pneumonias. Am J Respir Crit Care Med 188: 733-748, 2013. 